\title{
Solid-state NMR: An EYE Opener in Surface Chemistry
}

\author{
Matthew P. Conley and Christophe Copéret*
}

\begin{abstract}
Solid-state NMR plays a critical role in establishing the atomic structure of surface species, obtained by the controlled grafting of organometallic complexes onto amorphous oxide supports, a promising strategy towards molecularly defined heterogeneous catalysts. Using one-dimensional or multi-dimensional NMR analysis allows us to map the structure of organometallic residues on surfaces, in a similar fashion that the structure of homogeneous catalysts can be determined using solution NMR techniques. In addition, chemical shift anisotropy analysis can be used as a tool to obtain detail structures and to determine the dynamics of surface species. In combination with DFT calculations we have also shown that the structure of aluminum species can be determined using high-field and ultrafast ${ }^{27} \mathrm{AI}$ NMR. Finally, we discussed the latest development in Dynamic Nuclear Polarization, which allows the selective enhancements of the NMR signals of surface species, thus reducing the NMR acquisition time by factors up to 10,000. This makes solid-state NMR an indispensible tool in determining structure-property relationship and in the development of advanced materials including catalysts through more rational approach.
\end{abstract}

Keywords: DNP-SENS NMR · Dynamic nulear polarization (DNP) · Solid-state NMR · Surface chemistry

\section{Introduction}

Bridging the gap between molecular and solid-state chemistry has been a longterm research goal in our laboratory, addressing in particular the development of well-defined heterogeneous catalysts. ${ }^{[1,2]}$ Heterogeneous catalysts are complex materials that have surface active sites, which can be either isolated species on a support or an ensemble of atoms on a nanoparticle. The complexity of these systems leads to general difficulties when accessing the nature and the structure of the active sites, and obviously restricts the use of structure-activity relationships or other rational improvement strategies that could lead to better catalysts. The often elusive understanding of these catalytically active sites is in stark contrast to homogeneous catalysis, where the catalytic sites are based on single-metal atoms coordinated to ligands in well-defined chemical environments. Combining the advantages of homogeneous catalysts (well-defined sites) and

${ }^{\star}$ Correspondence: Prof. C. Copéret ETH Zürich, Department of Chemistry Wolfgang Pauli Strasse, 10 $\mathrm{CH}-8093$ Zürich

E-mail: ccoperet@inorg.chem.ethz.ch those provided by heterogeneous systems (more efficient chemical processes) should provide access to 'optimal' catalysts.

The generation of well-defined surface species by controlling material surface functionalities including organometallic entities has been our research strategy. First, this requires knowledge of the chemical nature and the density of surface functional groups. Identification of the surface-grafted organometallic species, and how the organometallic species progress under reaction conditions, are critical steps in the understanding of a well-defined heterogeneous catalyst. Each step obviously calls for the use of advanced spectroscopic techniques.

In this respect, X-ray diffraction is an essential tool to understand the structure of molecular species and crystalline solids, but it requires structural regularity that is rarely present on surfaces. Other X-ray based techniques, such as XANES and EXAFS, provide crucial information about oxidation state and the direct environment of the surface metal sites. Vibrational spectroscopy also yields information about the surface functionalities, and can be particularly useful to monitor chemical transformations on surfaces, but is restricted to rather simple systems and specific groups. The most powerful method to determine molecular structure and dynamics is clearly NMR. However, the low concentration of surface species in and the low inherent sensitivity of NMR have clearly impeded a broader general application of this technique. Selective labeling and recent advances in polarization techniques that selectively enhance surface NMR signals alleviate some of these complications In this perspective we will discuss our efforts to determine the structure of surface species at the molecular level, focusing on how solid-state NMR has helped us in this endeavor. ${ }^{[3]}$

\section{Determining Molecular Structure and Connectivity of Well-defined Surface Species Supported on Oxide Materials}

A key step of the preparation of welldefined surface species involves the grafting of an organometallic or metallorganic complex on hydroxyl groups present on the surface of oxide materials such as silica or alumina. The density of surface hydroxyl units can be controlled by a thermal pretreatment at high temperatures under high vacuum or a flow of inert gas. For example, silica nanoparticles can be treated up to $700{ }^{\circ} \mathrm{C}$ under high vacuum without a significant loss of surface area, but this does result in a decrease of the surface $\mathrm{Si}-\mathrm{OH}$ density to about $0.7 \mathrm{OH} \mathrm{nm}^{-2}$. Reacting these particles with organometallic complexes replaces a reactive $\mathrm{M}-\mathrm{X}$ ligand to yield a monodentate M-OSi ligand on the surface. Scheme 1 shows a few examples of grafted organometallic complexes using this route.

Each of the structures in Scheme 1 was fully resolved using solid-state NMR spectroscopy. It is first noteworthy that ${ }^{1} \mathrm{H}$ NMR spectra can be obtained with reasonable spectral resolution $\left(\Delta_{1 / 2}=200-300 \mathrm{~Hz}\right)$ 


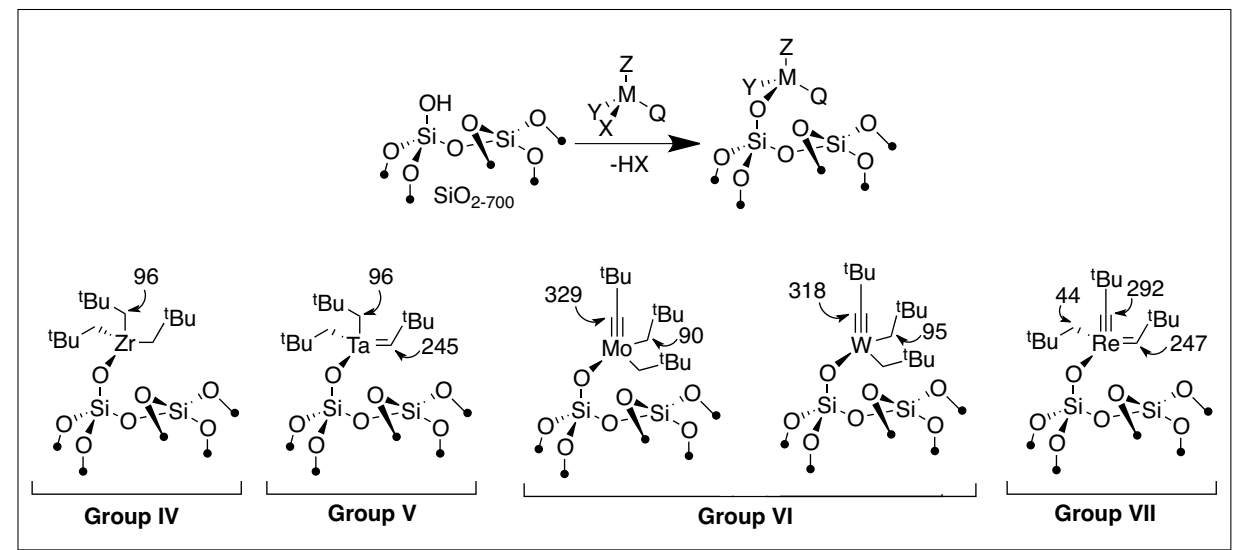

Scheme 1. Representative examples of surface organometallic species with ${ }^{13} \mathrm{C}$ CPMAS NMR chemical shifts (ppm). using standard magic angle sample spinning rates $\left(v_{\mathrm{MAS}}=5-12 \mathrm{kHz}\right)$ in the absence of ${ }^{1} \mathrm{H}-{ }^{1} \mathrm{H}$ decoupling. This is due to the low density of protons of these systems in contrast to typical materials, which suffer from tremendous line broadening (vide infra, section 5). ${ }^{[4,5]}$ The resolution can be slightly improved by implementing a spinecho into the pulse sequence or decoupling strategies (CRAMPS), allowing $\Delta_{1 / 2}<100$ Hz. ${ }^{[6]}$

Solving the structure of surface species requires ${ }^{13} \mathrm{C} \mathrm{NMR}$, which benefits from a much larger chemical shift window than ${ }^{1} \mathrm{H}$ NMR. However, obtaining high quality spectra requires the use of ${ }^{13} \mathrm{C}$ labeled samples in view of the low natural abundance of ${ }^{13} \mathrm{C}(1.1 \%)$, a less NMR receptive nucleus compare to hydrogen $\left(\gamma_{\mathrm{C}} / \gamma_{\mathrm{H}}\right.$ $=0.25)$, and the low content of surface species ( $c a .0 .2 \mathrm{mmol}$ per gram of silica). Cross polarization (CP) techniques under Hartman-Hahn conditions are typically used to further improve signal to noise ratio. Under these optimal conditions, the structure of a wide range of surface species has been possible. ${ }^{[1,2]}$ Scheme 1 shows a few examples of $\mathrm{Zr},{ }^{[7-9]} \mathrm{Ta},{ }^{[10]} \mathrm{Mo},{ }^{[4,10]}$ $\mathrm{W},{ }^{[10,11]}$ and $\mathrm{Re}^{[10,12]}$ complexes on silica supports that have been characterized using ${ }^{13} \mathrm{C}$ CPMAS spectroscopy. pounds in solution, multidimensional NMR spectroscopy is often needed to confirm assignments made from the 1D spectra. For instance, 2D heteronuclear correlation NMR (HETCOR) is used to establish the connectivity within organometallic fragments of surface species by exploiting dipolar interactions between neighboring atoms. For surface species, short contact times $(0.2-0.5 \mathrm{~ms})$ give correlations between spins that are 'close' to one another, effectively giving correlations only between protons directly bound to carbons. HETCOR spectra have been critical in assigning a number of surface species that are active olefin metathesis cata-
As in the characterization of com- lysts. ${ }^{[5,6,13]}$ This powerful tool has in fact been used to establish the structure of each olefin metathesis intermediate by monitoring the reaction of di-labeled ${ }^{13} \mathrm{C}$-ethylene with a well-defined silica supported tungsten alkene metathesis catalyst $[(\equiv \mathrm{SiO}) \mathrm{W}$ $\left.(\equiv \mathrm{NAr})(=\mathrm{CH} t \mathrm{Bu})\left(2,5-\mathrm{Me}_{2} \mathrm{NC}_{4} \mathrm{H}_{2}\right)\right] \quad$ (Fig. 1). ${ }^{[14]}$ The terminal methylidene species (1$\mathbf{C H}_{2}$ ) and two metallacyclobutane intermediates with either trigonal bipyramidyl (1TBP) or square-pyramid (1-SBP) geometries are readily assigned using HETCOR spectroscopy.

Another powerful technique is ${ }^{1} \mathrm{H}-{ }^{1} \mathrm{H}$ double-quantum NMR spectroscopy, which probes the presence of adjacent protons. ${ }^{[16,17]}$ This provides a 2D map where two protons $\left(\mathrm{H}_{\mathrm{A}}\right.$ and $\left.\mathrm{H}_{\mathrm{B}}\right)$ that are dipolar coupled appear as cross-peaks at the sum of the two respective frequencies $\left(\delta_{A}+\delta_{B}\right)$ in the indirect dimension $\left(F_{1}\right)$. Equivalent neighboring protons $\left(\mathrm{H}_{\mathrm{C}}\right)$ that have the same chemical shift $\left(\delta_{\mathrm{C}}\right)$ in $F_{2}$ give rise to an autocorrelation peak at $2 \times \delta_{\mathrm{C}}$. Spins that are not dipolar coupled do not appear in these spectra. The double quantum NMR technique has allowed us to discriminate between silica-supported zirconium monohydride and zirconium dihydride species, which together constitute a low temperature hydrogenolysis and homologation of alkane catalyst (Fig. 2). [7-9] nucleus to characterize surface species. Although ${ }^{31} \mathrm{P}$ has a lower NMR sensitivity than hydrogen $\left(\gamma_{\mathrm{P}} / \gamma_{\mathrm{H}}=0.40\right)$, the $100 \%$ natural isotopic abundance allows relatively fast acquisition of ${ }^{31} \mathrm{P}$ NMR spectra. This nucleus is also particularly interesting because of organophosphorus compounds are classical ligands in organometallic and coordination chemistry. For example, we recently probed the difference of environment of surface Au(I) complexes by addition of $\mathrm{PMe}_{3}$, which showed the presence of two surface species that had either one and two $\mathrm{PMe}_{3}$ ligands (Fig. 3). The nature of the surface species was confirmed by a 1D INADEQUATE (Incredible Natural
Phosphorus-31 is also an ideal NMR

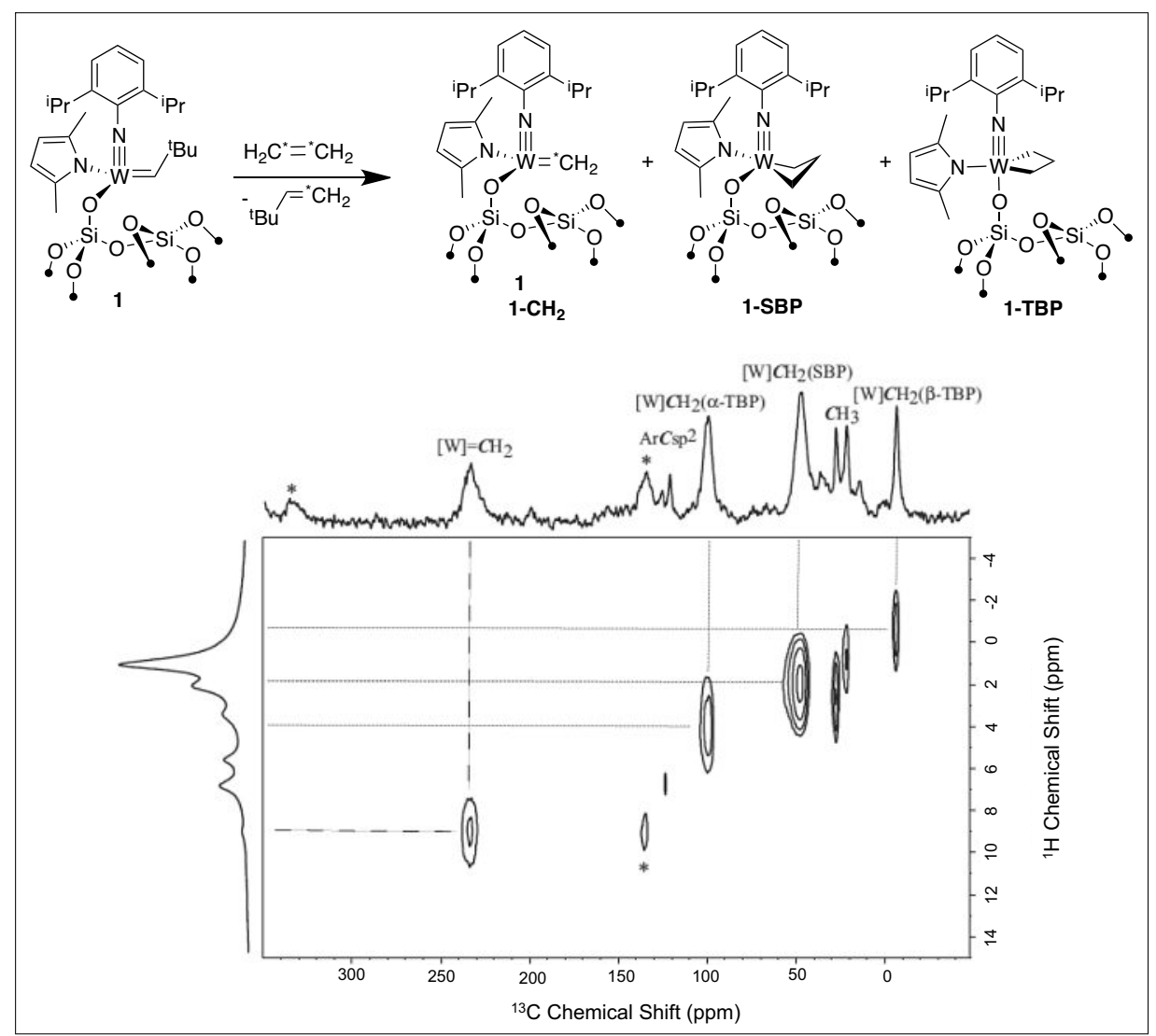

Fig. 1. ${ }^{1} \mathrm{H}-{ }^{13} \mathrm{C}$ HETCOR spectrum of silica-supported tungsten metathesis intermediates. All three expected intermediates $\mathbf{1 -} \mathbf{C H}_{2}, \mathbf{1 - T B P}$, and 1-SBP are observed. ${ }^{[15]}$ 


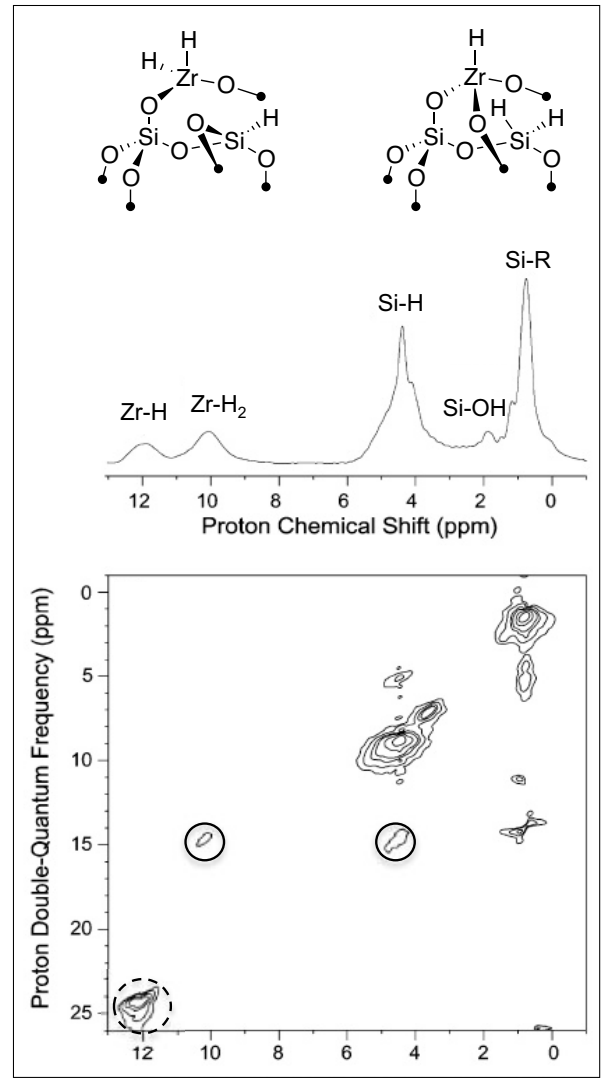

Fig. 2. Double quanta proton-proton multidimensional NMR spectrum which discriminates between ( $\equiv \mathrm{SiO})_{2} \mathrm{Zr}(\mathrm{H})_{2}$ (auto correlation highlighted with dotted circle) and (三SiO) $2 \mathrm{Zr}-\mathrm{H}$ (correlation with surface $\mathrm{SiH}$, solid line). Adapted with permission from the authors. ${ }^{[9]}$

Abundance DoublE QUAntum Transfer Experiment) experiment which clearly showed that one of these signals corresponded a $\mathrm{Au}\left(\mathrm{PMe}_{3}\right)_{2}^{+}$cationic surface species that is non-covalently bound to the surface though an anionic siloxide ionpair. ${ }^{[18]}$

\section{Access to Electronic structures and Dynamics of Surface Species}

Solid-state NMR can also be helpful in providing information about the electronic structure and the dynamics of surface species from the chemical shift anisotropy (CSA) of surface sites. The CSA is a tensorial value, which reflects the orientation dependence of the chemical shift in an external magnetic field and the anisotropy of the electron distribution around a nucleus, and thereby provides details about orbital hybridization of the nucleus. The CSA is characterized by the three principal components of a second rank tensor $\left(\delta_{11}, \delta_{22}, \delta_{33}\right)$, which is often described by the three following values using the Haeberlen convention: the isotropic chemical shift $\delta_{\text {iso }}$, which is the average of the three values $\left(\delta_{\text {iso }}=\right.$ $1 / 3\left(\delta_{11}+\delta_{22}+\delta_{33}\right)$, the anisotropic chemical shift $\delta_{\text {aniso }}\left(\delta_{\text {aniso }}=\delta_{11}-\delta_{\text {iso }}\right)$ and the asymmetry parameter $\eta \quad \eta=\frac{\left(\delta_{22}-\delta_{11}\right)}{\left(\delta_{33}-\delta_{\text {iso }}\right)}$. In solution, $\delta_{\text {iso }}$ is the only observable value as a result of rapid molecular tumbling. In rigid solids, the CSA is not averaged, and the line shapes - the powder pattern - allow a 'direct' reading of the principal chemical shift components. If dynamic behavior is present the spectrum then lies in between the CSA of the static and the fully dynamic system associated with a single harp line at the isotropic value. Comparison of the experimental CSA to static CSA patterns obtained by DFT calculations, gives quantitative information of the systems dynamics. This CSA analysis also yields information on the hybridization of carbon nuclei.

We have exploited these features of the CSA to understand the nature of a series of surface alkylidene metal complexes. Analysis of the experimental CSA to the DFT-obtained static CSA spectrum revealed that large aromatic ligands freeze dynamics of mono-grafted surface complexes, even though the complexes are bound to the surface by only a single 三Si-O-M linkage (Fig. 4a). We also found that the orientation of the CSA is a direct measure of the strength of the agostic interaction between the metal and the alkylidene $\mathrm{C}-\mathrm{H}$. The most shielded component $\left(\delta_{33}\right)$ is aligned along the p-orbital of the alkylidene ligand, as in $s p^{2}$ hybridized carbon, for weak agostic interactions; and approaches a $\mathrm{M} \equiv \mathrm{C}$ alkylidyne type bond, as

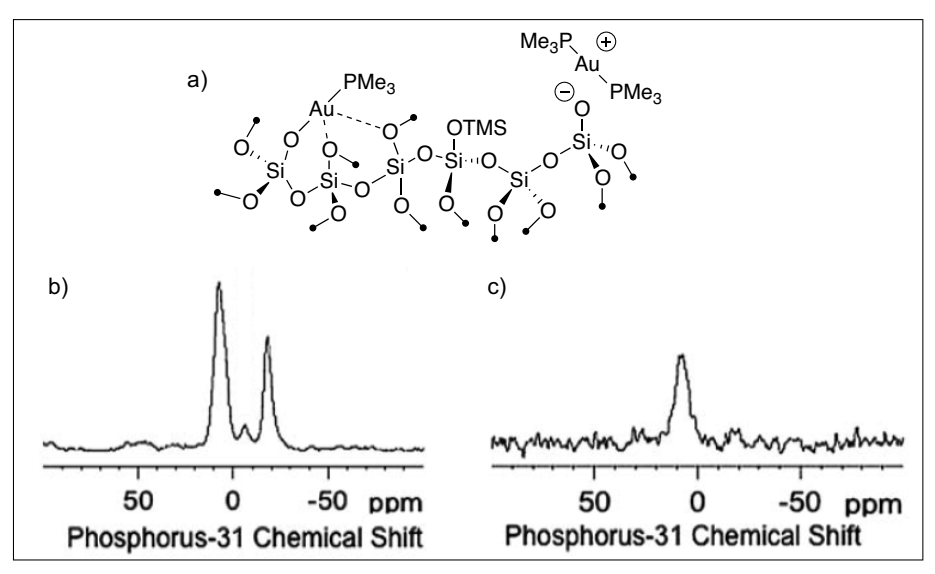

Fig. 3. a) Structure of $\left[\left(\equiv \mathrm{SiO} \mathrm{AuPMe}_{3}\right]\right.$ and the $\left[\mathrm{Au}\left(\mathrm{PMe}_{3}\right)_{2}\right]$ [OSi $\equiv]$ ion pair; b) ${ }^{31} \mathrm{P}$ CPMAS spectrum, which contains peaks for two different surface phosphorus species; c) INADEQUATE 1D NMR spectrum that establishes only the peak at $8 \mathrm{ppm}$ has ${ }^{31} \mathrm{P}-{ }^{31} \mathrm{P}$ coupling. Adapted with permission from the authors. ${ }^{[18]}$ in $s p$ hybridized carbon, for strong agostic interactions (Fig. 4b). ${ }^{[19]}$ These findings are in excellent agreement with the ${ }^{1} J_{\mathrm{CH}}$ obtained for the alkylidene $\mathrm{C}-\mathrm{H}$, which decreases in value as the orbital becomes more $s p$-like.

\section{4. ${ }^{27}$ Al NMR Spectroscopy: A Rendez-vous with Quadrupolar Nuclei}

Because of its quadrupolar nature, which is associated with an anisotropic distribution of electric charge around the nucleus, aluminum-27 $(I=5 / 2$, natural abundance: $\left.100 \%, \gamma_{\mathrm{Al}} / \gamma_{\mathrm{H}}=0.26\right)$ has a very sensitive NMR signature. The NMR properties depend directly on the number and type of ligands directly bound to aluminum in the first-coordination sphere, and the geometry of the species. Quadrupolar nuclei are associated with a quadrupolarcoupling constant $\left(C_{Q}\right)$, which can reach several $\mathrm{MHz}$, and an asymmetry parameter $(\eta)$. This often results in dramatic broadening of the signal, which causes obvious detection problems, though this does lead to characteristic signal patterns for different aluminum species.

One case that shows the power of solidstate ${ }^{27} \mathrm{Al}$ NMR spectroscopy is the identification of aluminum sites in alumina and zeolites because tetra-, penta-, and hexacoordinated aluminum have distinct isotropic chemical shifts $\left(\delta_{\text {iso }}\right) \cdot{ }^{[20]}$ However, structural determination of surface organoaluminum species, for example the chemisorption of organoaluminum compounds on silica, remains a distinct challenge because assignment from only the $\delta_{\text {iso }}$ can be misleading. It is of paramount importance to access $C_{Q}$ and $\eta$, which in combination with $\delta_{\text {iso }}$ provides a robust model to understand the first-coordination sphere of the aluminum sites.

We recently solved the structure of surface organoaluminum species resulting from the reaction of $\mathrm{Et}_{3} \mathrm{Al}$ on silica, using mesoporous SBA-15 silica dehydroxylated at $500{ }^{\circ} \mathrm{C}$. This chemistry represents a long-standing challenge because the surface chemistry is quite complex; organoaluminum compounds react readily with surface silanol and siloxane bridges. ${ }^{[21,22]}$ Additionally, silica-supported organoaluminum reagents are a promising class of heterogeneous activators for olefin polymerization catalysts, which would offer an advantageous alternative to the commonly used solutions of methaluminooxane (MAO). Ultrafast spinning rates $(>60$ $\mathrm{kHz}$ ) and NMR experiments at several of the highest available magnetic fields (17.6, 20.0, and 23.5 T) were necessary to extract and confirm the NMR signatures $\left(\delta_{\text {iso }}, C_{Q}\right.$ and $\eta$ ) of the three different aluminum 


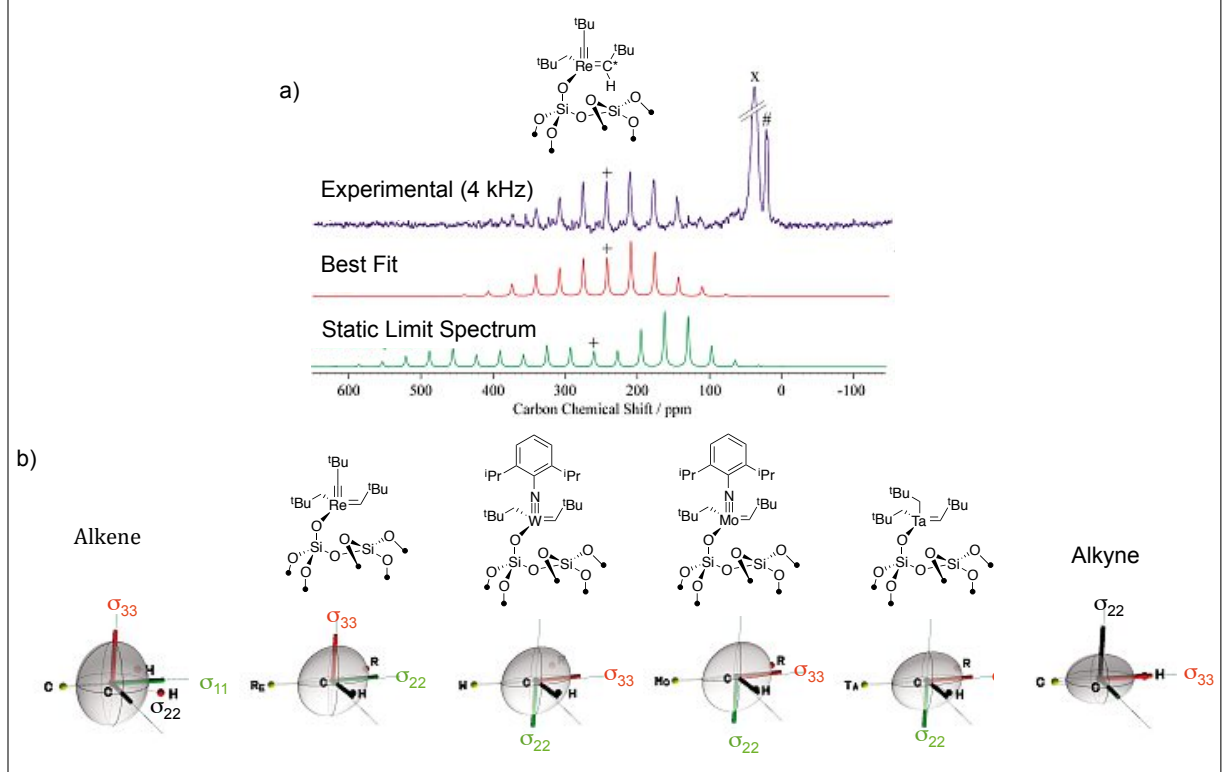

Fig. 4. a) CSA analysis of a surface Re carbene, the experimental spectrum (top, blue) was fit to obtain the CSA of the species (middle, red) and compared to the static spectrum (bottom, green) obtained from DFT calculations; b) POV-RAY diagrams showing the change in orbital hybridization for different metal alkylidenes with agostic interactions. Adapted with permission from the authors.

sites formed upon $\mathrm{Et}_{3} \mathrm{Al}$ grafting on dehydroxlated SBA-15. ${ }^{[23]}$ We reconstituted the structure of each surface site by aligning the experimental results with DFT calculations on cluster and periodic models. Two aluminum sites that correspond to a dinuclear $\mathrm{Al}$ species grafted either via two terminal or two bridging $\mu^{2}$-siloxy groups were identified as matching both theoretical and experimental data (Fig. 5). The third $\mathrm{Al}$ species arises from the incorporation of $\mathrm{Al}$ into the silica framework, forming a tetrahedral site.

\section{Latest Developments in Characterizing Surface Functionalities in Functional Materials}

Though grafting organometallic complexes on oxide supports generates welldefined surface species, a plethora of other ligands are known to coordinate metals. With the aim to retain site isolation and single-site behavior, we have utilized solgel techniques in the presence of a structure-directing agent to obtain mesoporous hybrid silica organic materials that contain organic functionalities regularly placed inside the mesopores, whose diameter can be tuned between 4 to $10 \mathrm{~nm}$ (Scheme 2).[24,25]

This approach is quite general, and we have reported materials containing imidazolium compounds, which are precursors to $\mathrm{N}$-heterocyclic carbene metal complexes. These NHC-M containing materials have been shown to be effective catalysts for Ir-catalyzed H/D exchange, [26] and $\mathrm{Ru}$-catalyzed olefin metathesis ${ }^{[27]}$ and
$\mathrm{CO}_{2}$ reduction ${ }^{[28]}$ with performance close the analogous homogeneous catalysts. However, the solid-state NMR characterization of the imbedded ligands and the resulting organometallic complexes have remained a challenge, since by design these materials have very low organic concentrations ( $c a .0 .1-0.5 \mathrm{mmol} \mathrm{g}^{1}$ ) so the ligated metal complexes behave as single catalytic sites. Moreover, they also display much higher proton densities, from surface silanols or surface passivating agents, than corresponding catalysts prepared by grafting on highly dehydroxylated silica, which results in tremendous line broadening in ${ }^{1} \mathrm{H}$ NMR spectra.

The first challenge results from high proton density, in which case fast sample spinning is essential for high quality ${ }^{1} \mathrm{H}$ NMR spectra. Fig. 6 shows the dramatic effect fast sample spinning has on the proton NMR linewidths of MatPhOH, a hybrid material that contains regularly placed phenol units within the mesopores. ${ }^{[29]} \mathrm{At}$ $10 \mathrm{kHz}$ magic angle spinning (MAS) the ${ }^{1} \mathrm{H}$ NMR spectrum is dominated by the large $\mathrm{Si}-\mathrm{OH}$ signal at $1.5 \mathrm{ppm}$ (Fig. 6a). Though higher frequency aromatic resonances are distinguishable from the Si$\mathrm{OH}$ signal it is difficult to identify other potential surface species from this NMR spectrum. Increasing the spinning rate to $60 \mathrm{kHz}$ sharpens the aromatic signals, and also unmasks the phenolic hydrogen, and ethoxy surface groups that were previously covered by the $\mathrm{SiOH}$ resonance (Fig. 6b).

The second challenge then lies in ac-

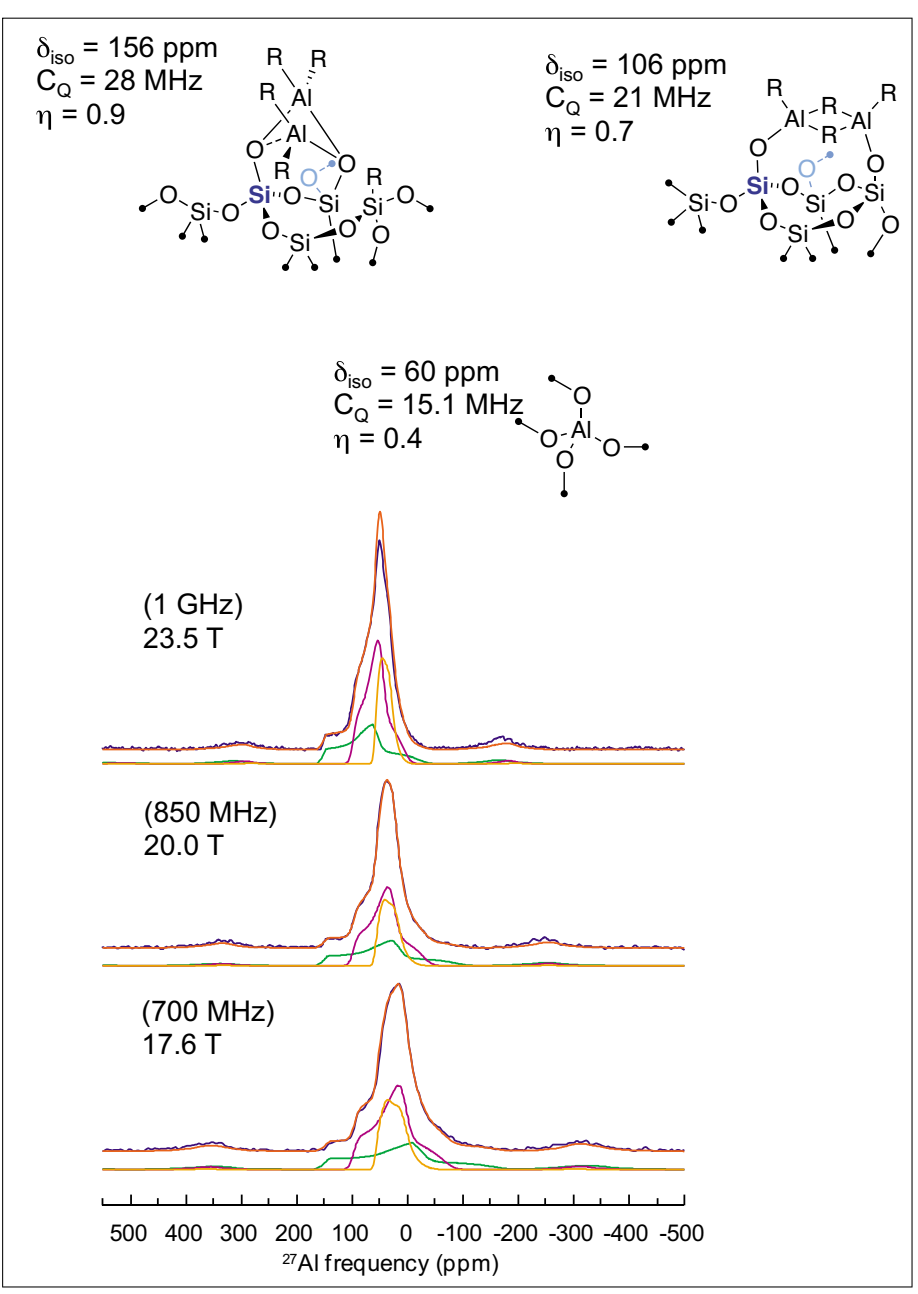

Fig. 5. Structures of surface aluminum species grafted on SBA determined from ${ }^{27} \mathrm{Al}$ NMR studies (top) and ${ }^{27} \mathrm{Al} \mathrm{NMR}$ spectra, which were collected at 700,850 , and $1000 \mathrm{MHz}$, respectively (bottom) 

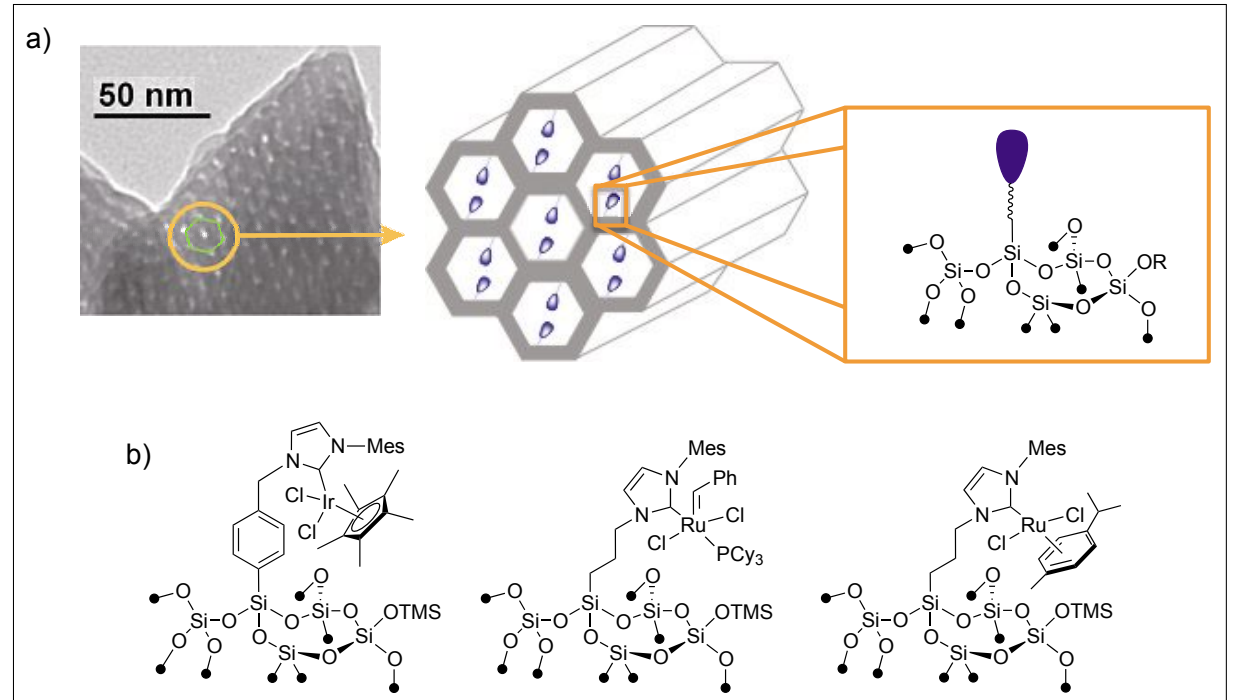

Scheme 2. Mesoporous hybrid organic silica containing organic fragments inside the large pores; a) TEM and model showing SBA; b) Representative SBA materials with NHC-M complexes in the material.

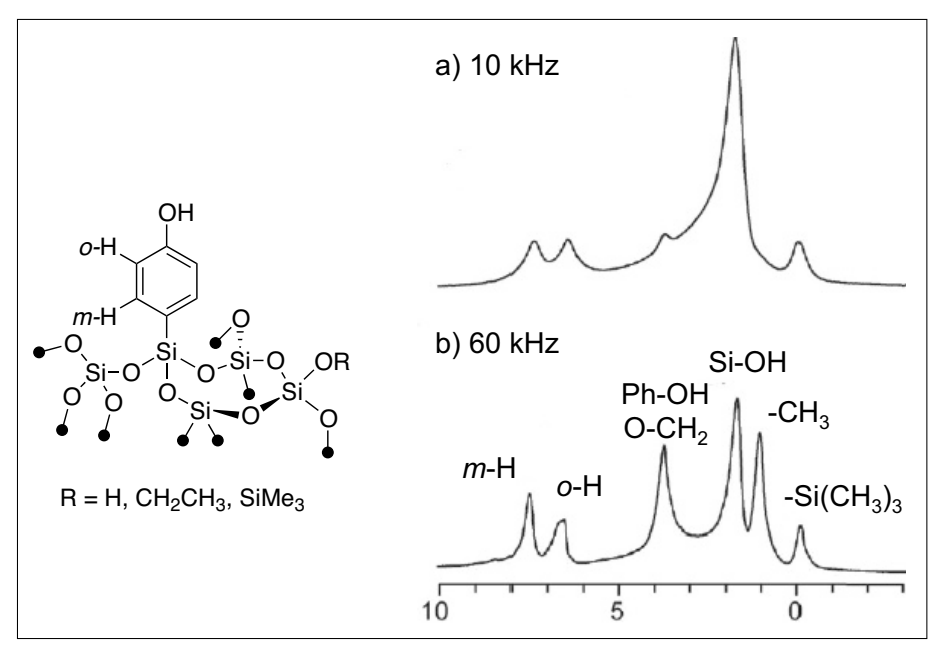

a)

b)

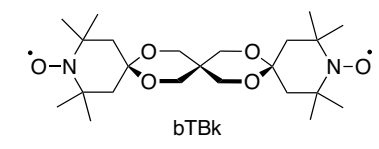

c)

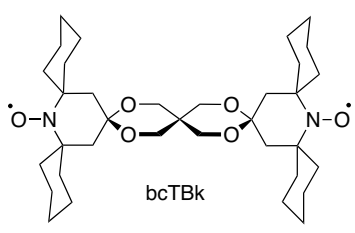<smiles>CC1(C)CC(NC(O)COC2CC(C)(C)N(O)C2(C)C)C(C)(C)N1O</smiles>

Fig. 6. Comparison of ${ }^{1} \mathrm{H}$ NMR spectra at of MatPhOH at different sample spinning rates, a) $10 \mathrm{kHz}$; b) $60 \mathrm{kHz}$. ${ }^{[29]}$ quiring high-quality ${ }^{13} \mathrm{C}$ and ${ }^{29} \mathrm{Si} \mathrm{NMR}$ spectra in reasonable acquisition times. 1D ${ }^{13} \mathrm{C}$-CPMAS NMR experiments typically require $12-24 \mathrm{~h}$ to obtain spectra, with at best reasonable signal to noise, which severely limits the use of advanced multidimensional NMR techniques. Indeed, many solid-state NMR studies of hybrid materials require tedious isotopic enrichment to obtain reasonable $1 \mathrm{D}{ }^{13} \mathrm{C}$ NMR spectra. ${ }^{[26-28]}$ Similarly, ${ }^{29} \mathrm{Si}$ NMR can require many days to obtain a spectrum under inert conditions.

Recently we showed that Surface Enhanced NMR spectroscopy by Dynamic Nuclear Polarization ${ }^{[30-34]}$ (DNP-SENS NMR) provides sensitivity gains that result in high quality 1D and 2D NMR spectra of surface species in very short experiment times (minutes) at natural isotopic abundance. ${ }^{[35-40]}$ In DNP-SENS NMR a solution of a persistent radical polarizing agent ${ }^{[41-43]}$ is introduced to a material by incipient wetness impregnation. Continuous wave microwave irradiation of the EPR transition at $c a .100 \mathrm{~K}$ induces a polarization transfer from the electrons of the radical to the protons of the solvent and surface nuclei. The enhanced ${ }^{1} \mathrm{H}$ polarization is transferred by $\mathrm{CP}$ to heteronuclei (e.g. ${ }^{13} \mathrm{C},{ }^{29} \mathrm{Si},{ }^{15} \mathrm{~N},{ }^{27} \mathrm{Al}$ ). DNP-SENS NMR spectroscopy dramatically reduces experiment time by up a factor up to 10,000 , and allows the detailed structural characterization of surface species.

Our initial efforts started at EPFL where we aimed to characterize functional materials. Incipient wetness impregnation of MatPhOH with aqueous TOTAPOL [44] (Fig. 7a) solutions resulted in a ${ }^{13} \mathrm{C} \mathrm{CPMAS}$ signalenhancement $\left(\varepsilon_{\mathrm{C}, \mathrm{CP}}\right)$ of 57 (Fig. $\left.7 \mathrm{~d}\right) .^{[45]}$ The signal enhancement value corresponds to the square of experiment time, indicating a reduction by 3100 in experiment time with respect to classical NMR. These signal enhancements allowed us to obtain a ${ }^{1} \mathrm{H}-{ }^{13} \mathrm{C}$ HETCOR experiment without isotopic enrichment in only $c a .4$ h. We have also shown in related studies that TOTAPOL is an effective polarization transfer agent for ${ }^{29} \mathrm{Si} \mathrm{NMR}^{[36]}$ and ${ }^{27} \mathrm{Al}$ studies. ${ }^{[46]}$

In order to investigate a larger palette of solids that eventually contain reactive sites like catalysts we have shifted our focus to diradicals that are soluble in organic solvents, because many metal-containing materials are incompatible with aqueous conditions. Initial experiments were performed with organic solutions of bisTEMPO-bisketal (bTBk, Fig. 7b), ${ }^{[47]}$ a diradical with superior enhancement properties compared to TOTAPOL. Solvent optimization established that chlorinated solvents give the best enhancements with bTBk with MatPhOH material.

We applied this result to a hydrophobic surface yttrium complex coordinated
Fig. 7. Biradicals for DNP-SENS NMR and a DNP-SENS NMR spectrum of MatPhOH with microwaves ON and OFF. The $\varepsilon_{\mathrm{C}, \mathrm{CP}}$ for this spectrum is 57 ; a) TOTAPOL; b) bTBk; c) bcTBk; d) ${ }^{13} \mathrm{C}$ CPMAS spectrum of aqueous TOTAPOL wetted MatPhOH with microwave ON (top) and OFF (bottom). $\mu$ Wave OFF

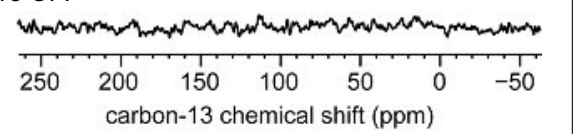


to a light-harvesting bipyridyl ligand, ${ }^{[48]}$ and for the first time were able to characterize a surface inorganic complex with multinuclear DNP-SENS NMR (Fig. 8). ${ }^{[37]}$ Particularly noteworthy is that this material has a very low surface density of yttrium complexes (ca. $\left.0.2 \mathrm{~nm}^{2}\right)$ and acquisition of a ${ }^{1} \mathrm{H}-{ }^{13} \mathrm{C}$ HETCOR spectrum would be unimaginable using conventional solidstate NMR at natural isotopic abundance. The use of chlorinated organic solvents is general, and we have used this approach to characterize functionalized metal organic frameworks with DNP-SENS NMR. ${ }^{[49]}$

Greater enhancements have been obtained by inclusion of spiro-cyclohexyl groups adjacent to the nitroxyl unit in place of the gem-dimethyl units, which yields bis-cyclohexyl-TEMPO-bisketal (bcTbK, Fig. 7c). ${ }^{[50]}$ The higher DNP enhancements is likely due to the longer electron longitudinal relaxation time for $\mathrm{bCTbK}$, which is 1.7 times longer than that of bTBk. Under optimal conditions hybrid materials wetted with 1,1,2,2-tetrachloroethane solutions of bcTbK gave ${ }^{29} \mathrm{Si}$ CPMAS enhancements values $\left(\varepsilon_{\mathrm{Si}, \mathrm{CP}}\right)$ up to 113 for NMR experiments, corresponding to a reduction in experiment time by a factor of 12,000 . This result encouraged us to pursue natural abundance ${ }^{15} \mathrm{~N}$ CPMAS NMR, which is particularly challenging due to the low NMR sensitivity $\left(\gamma_{\mathrm{N}} / \gamma_{\mathrm{H}}=0.1\right)$ and low natural abundance of ${ }^{15} \mathrm{~N}(0.3 \%)$. This allowed us to monitor the functional group manipulation of a material at natural abundance by ${ }^{15} \mathrm{~N}$ CPMAS DNP-SENS NMR (Fig. 9).

The ${ }^{15} \mathrm{~N} N M R$ spectrum of the azido material gives the expected three peaks for the three separate nitrogen atoms. Reduction of the azide under Staudinger conditions gives a primary amino group on the surface. The ${ }^{15} \mathrm{~N}$ CPMAS spectrum contains signals primarily for the amino group, with a small amount of surface azide remaining as the only byproduct. Conversion of the surface amine to the imidazolium salt under mildly acidic conditions gave the
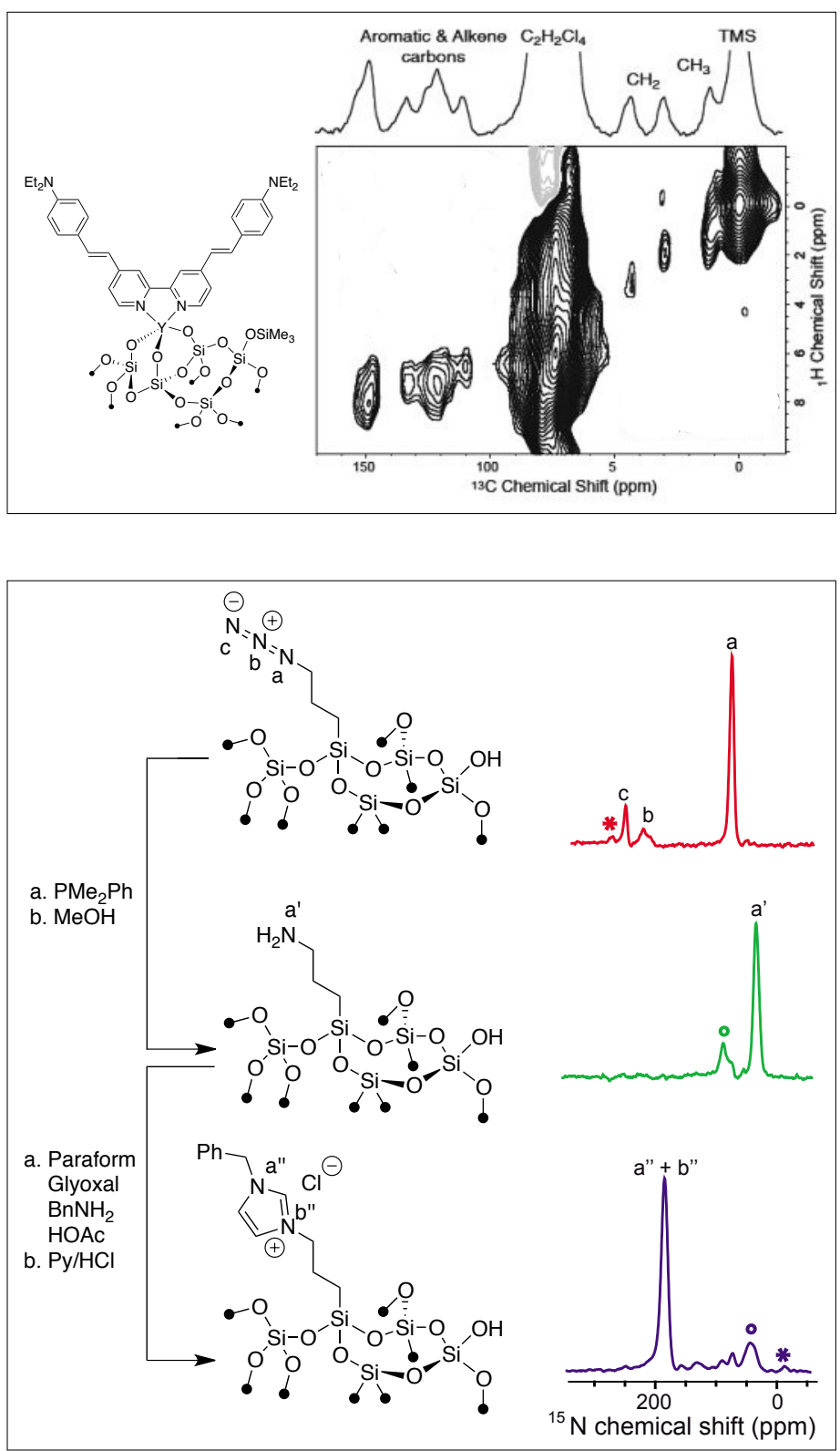

surface NHC precursor. Notably each of these reactions proceeds without detectable byproducts, only the product and residual unreacted resonances are observed. These recent advances have introduced a new paradigm for investigating surfaces and inorganic solids by solid-state NMR.

\section{Conclusions}

Solid-state NMR is an essential tool for understanding the molecular level behavior of surface species. We have characterized both structure and dynamics of surface organometallic complexes, opening new avenues in the interpretation of how metals behave on inorganic surfaces. This could eventually give access to quantitative structure-reactivity relationships that will lead to the development of efficient heterogeneous catalysts by a more rational approach. Also paramount to our studies of surface species is the integration of DFT calculations to guide the interpretation of experimental results, which was shown in the static CSA determination of surface organometallic complexes and the ${ }^{27} \mathrm{Al}$ NMR study of surface aluminum species. Finally, recent exciting advances in SENS NMR spectroscopy selectively increase the NMR signal of surface sites. This gives information that is often impossible with other solid-state spectroscopy methods, and will push the study of surface species and ultimately give new insights to the molecular behavior of inorganic solids. Further work in these directions is currently under way.

\section{Acknowledgements}

We would like to thank Lyndon Emsley Fig. 9. Conversion of a surface azide to a surface imidazolium via reduction to an amine followed by ${ }^{15} \mathrm{~N} \mathrm{NMR}$ at natural abundance using DNP-SENS NMR. and Anne Lesage of C-RMN (Lyon) for a long-standing and fruitful collaboration in the area of solid-state NMR spectroscopy, Pierre Florian and Dominique Massiot for having made us discover the area of quadrupolar nuclei and G. Bodenhausen (EPFL) for giving us the opportunity to start the structural investigation of solids by dynamic nuclear polarization.

Received: July 31, 2012

[1] C. Copéret, M. Chabanas, R. Petroff SaintArroman, J.-M. Basset, Angew. Chem. Int. Ed. 2003, 42, 156.

[2] J.-M. Basset, J.-P. Candy, C. Copéret in 'Surface Organometallic Chemistry', in 'Comprehensive Organometallic Chemistry III: From Fundamentals to Applications', Eds. R. Crabtree, M. Mingos, Elsevier, 2006.

[3] F. Blanc, C. Coperet, A. Lesage, L. Emsley, Chem. Soc. Rev. 2008, 37, 518.

[4] R. Petroff Saint-Arroman, M. Chabanas, A. Baudouin, C. Copéret, J. H. Basset, A. Lesage, L. Emsley, J. Am. Chem. Soc. 2001, 123, 3820.

[5] M. Chabanas, A. Baudouin, C. Copéret, J.-M. Basset, W. Lukens, A. Lesage, S. Hediger, L. Emsley, J. Am. Chem. Soc. 2003, 125, 492.

[6] F. Blanc, C. Copéret, J. Thivolle-Cazat, J.-M. 
Basset, A. Lesage, L. Emsley, A. Sinha, R. R. Schrock, Inorg. Chem. 2006, 45, 9587.

[7] C. Lecuyer, F. Quignard, A. Choplin, D. Olivier, J.-M. Basset, Angew. Chem. 1991, 103, 1692.

[8] C. Thieuleux, A. Maraval, L. Veyre, C. Copéret, D. Soulivong, J.-M. Basset, G. J. Sunley, Angew. Chem. Int. Ed. 2007, 46, 2288

[9] F. Rataboul, A. Baudouin, C. Thieuleux, L. Veyre, C. Copéret, J. Thivolle-Cazat, J.-M. Basset, A. Lesage, L. Emsley, J. Am. Chem. Soc. 2004, 126, 12541.

[10] F. Blanc, J.-M. Basset, C. Copéret, A. Sinha, Z. J. Tonzetich, R. R. Schrock, X. Solans-Monfort, E. Clot, O. Eisenstein, A. Lesage, L. Emsley, J. Am. Chem. Soc. 2008, 130, 5886.

[11] E. Le Roux, M. Taoufik, M. Chabanas, D. Alcor, A. Baudouin, C. Copéret, J. Thivolle-Cazat, J.-M. Basset, A. Lesage, S. Hediger, L. Emsley, Organometal. 2005, 24, 4274

[12] F. Rataboul, M. Chabanas, A. De Mallmann, C. Copéret, J. Thivolle-Cazat, J.-M. Basset, Chem. Eur. J. 2003, 9, 1426

[13] B. Rhers, A. Salameh, A. Baudouin, E. A. Quadrelli, M. Taoufik, C. Copéret, F. Lefebvre, J.-M. Basset, X. Solans-Monfort, O. Eisenstein, W. W. Lukens, L. P. H. Lopez, A. Sinha, R. R. Schrock, Organometal. 2006, 25, 3554.

[14] F. Blanc, R. Berthoud, C. Copéret, A. Lesage, L. Emsley, R. Singh, T. Kreickmann, R. R. Schrock, Proc. Nat. Acad. Sci. USA 2008, 105, 12123.

[15] F. Blanc, J. Thivolle-Cazat, J.-M. Basset, C. Copéret, Chem.-Eur. J. 2008, 14, 9030.

[16] S. P. Brown, H. W. Spiess, Chem. Rev. 2001, $101,4125$.

[17] S. P. Brown, I. Schnell, J. D. Brand, K. Mullen, H. W. Spiess, J. Am. Chem. Soc. 1999, 121, 6712.

[18] D. Gajan, D. Levine, E. Zocher, C. Copéret, A. Lesage, L. Emsley, Chem. Sci. 2011, 2, 928.

[19] F. Blanc, J.-M. Basset, C. Copéret, A. Sinha, Z. J. Tonzetich, R. R. Schrock, X. Solans-Monfort, E. Clot, O. Eisenstein, A. Lesage, L. Emsley, J. Am. Chem. Soc. 2008, 130, 5886.

[20] S. Sklenak, J. Dedecek, C. B. Li, B. Wichterlova, V. Gabova, M. Sierka, J. Sauer, Angew. Chem. Int. Ed. 2007, 46, 7286

[21] J. Li, J. A. DiVerdi, G. E. Maciel, J. Am. Chem. Soc. 2006, 128, 17093.

[22] J. Pelletier, J. Espinas, N. Vu, S. Norsic, A. Baudouin, L. Delevoye, J. Trebosc, E. Le Roux, C. Santini, J.-M. Basset, R. M. Gauvin, M. Taoufik, Chem. Commun. 2011, 47, 2979.

[23] R. N. Kerber, A. Kermagoret, E. Callens, P. Florian, D. Massiot, A. Lesage, C. Copéret,
F. O. Delbecq, X. Rozanska, P. Sautet, J. Am. Chem. Soc. 2012, 134, 6767.

[24] F. Hoffmann, M. Cornelius, J. Morell, M. Fröba, Angew. Chem. Int. Ed. 2006, 45, 3216.

[25] R. J. P. Corriu, A. Mehdi, C. Reye, J. Mater. Chem. 2005, 15, 4285.

[26] T. K. Maishal, J. Alauzun, J.-M. Basset, C. Copéret, R. J. P. Corriu, E. Jeanneau, A. Mehdi, C. Reyé, L. Veyre, C. Thieuleux, Angew. Chem. Int. Ed. 2008, 47, 8654 .

[27] I. Karamé, M. Boualleg, J.-M. Camus, T. K. Maishal, J. Alauzun, J.-M. Basset, C. Copéret, R. J. P. Corriu, E. Jeanneau, A. Mehdi, C. Reyé, L. Veyre, C. Thieuleux, Chem. Eur. J. 2009, 15, 11820.

[28] M. Baffert, T. K. Maishal, L. Mathey, C. Copéret, C. Thieuleux, ChemSusChem 2011, 4, 1762.

[29] A. Roussey, D. Gajan, T. K. Maishal, A. Mukerjee, L. Veyre, A. Lesage, L. Emsley, C. Copéret, C. Thieuleux, PhysChemChemPhys 2011, 13, 4230.

[30] L. R. Becerra, G. J. Gerfen, R. J. Temkin, D. J. Singel, R. G. Griffin, Phys. Rev. Lett. 1993, 71, 3561.

[31] M. Rosay, L. Tometich, S. Pawsey, R. Bader, R. Schauwecker, M. Blank, P. M. Borchard, S. R. Cauffman, K. L. Felch, R. T. Weber, R. J. Temkin, R. G. Griffin, W. E. Maas, PhysChemChemPhys 2010, 12, 5850.

[32] A. B. Barnes, G. De Paepe, P. C. A. van der Wel, K. N. Hu, C. G. Joo, V. S. Bajaj, M. L. Mak-Jurkauskas, J. R. Sirigiri, J. Herzfeld, R. J. Temkin, R. G. Griffin, Appl. Magn. Reson. 2008, 34, 237.

[33] T. Maly, G. T. Debelouchina, V. S. Bajaj, K. N. Hu, C. G. Joo, M. L. Mak-Jurkauskas, J. R. Sirigiri, P. C. A. van der Wel, J. Herzfeld, R. J. Temkin, R. G. Griffin, J. Chem. Phys. 2008, $128,19$.

[34] G. T. Debelouchina, M. J. Bayro, P. C. A. van der Wel, M. A. Caporini, A. B. Barnes, M. Rosay, W. E. Maas, R. G. Griffin, PhysChemChemPhys 2010, 12, 5911 .

[35] A. Lesage, M. Lelli, D. Gajan, M. A. Caporini, V. Vitzthum, P. Mieville, J. Alauzun, A. Roussey, C. Thieuleux, A. Mehdi, G. Bodenhausen, C. Copéret, L. Emsley, J. Am. Chem. Soc. 2010, 132, 15459.

[36] M. Lelli, D. Gajan, A. Lesage, M. A. Caporini, V. Vitzthum, P. Miéville, F. Héroguel, F. Rascon, A. Roussey, C. Thieuleux, M. Boualleg, L. Veyre, G. Bodenhausen, C. Coperét, L. Emsley, J. Am. Chem. Soc. 2011, 133, 2104.
[37] A. Zagdoun, A. J. Rossini, D. Gajan, A Bourdolle, O. Ouari, M. Rosay, W. E. Maas, P. Tordo, M. Lelli, L. Emsley, A. Lesage, C. Copéret, Chem. Commun. 2012, 48, 654

[38] V. Vitzthum, P. Mieville, D. Carnevale, M. A. Caporini, D. Gajan, C. Copéret, M. Lelli, A Zagdoun, A. J. Rossini, A. Lesage, L. Emsley, G. Bodenhausen, Chem. Commun. 2012, 48 , 1988.

[39] A. J. Rossini, A. Zagdoun, M. Lelli, J. Canivet, S. Aguado, O. Ouari, P. Tordo, M. Rosay, W. E. Maas, C. Copéret, D. Farrusseng, L. Emsley, A Lesage, Angew. Chem. Int. Ed. 2012, 51, 123.

[40] A. J. Rossini, A. Zagdoun, M. Lelli, D. Gajan, F. Rascon, M. Rosay, W. E. Maas, C. Copéret, A. Lesage, L. Emsley, Chem. Sci. 2012, 3, 108.

[41] C. S. Song, K. N. Hu, C. G. Joo, T. M. Swager, R. G. Griffin, J. Am. Chem. Soc. 2006, 128, 11385.

[42] Y. Matsuki, T. Maly, O. Ouari, H. Karoui, M. F. Le, E. Rizzato, S. Lyubenova, J. Herzfeld, T. Prisner, P. Tordo, R. G. Griffin, Angew. Chem. Int. Ed. 2009, 48, 4996

[43] A. Zagdoun, G. Casano, O. Ouari, G. Lapadula, A. J. Rossini, M. Lelli, M. Baffert, D. Gajan, L. Veyre, W. E. Maas, M. Rosay, R. T. Weber, C. Thieuleux, C. Copéret, A. Lesage, P. Tordo, L. Emsley, J. Am. Chem. Soc. 2012, 134, 2284.

[44] C. Song, K.-N. Hu, C.-G. Joo, T. M. Swager, R G. Griffin, J. Am. Chem. Soc. 2006, 128, 11385

[45] A. Lesage, M. Lelli, D. Gajan, M. A. Caporini, V. Vitzthum, P. Miéville, J. Alauzun, A. Roussey, C. Thieuleux, A. Mehdi, G. Bodenhausen, C. Copéret, L. Emsley, J. Am. Chem. Soc. 2010 132,15459

[46] V. Vitzthum, P. Mieville, D. Carnevale, M. A. Caporini, D. Gajan, C. Copéret, M. Lelli, A. Zagdoun, A. J. Rossini, A. Lesage, L. Emsley, G. Bodenhausen, Chem. Commun. 2012, 48 1988.

[47] Y. Matsuki, T. Maly, O. Ouari, H. Karoui, F. Le Moigne, E. Rizzato, S. Lyubenova, J. Herzfeld, T. Prisner, P. Tordo, R. G. Griffin, Angew. Chem. Int. Ed. 2009, 48, 4996.

[48] N. Rendón, A. Bourdolle, P. L. Baldeck, H. Le Bozec, C. Andraud, S. Brasselet, C. Copéret, O. Maury, Chem. Mater. 2011, 23, 3228.

[49] A. J. Rossini, A. Zagdoun, M. Lelli, J. Canivet, S. Aguado, O. Ouari, P. Tordo, M. Rosay, W. E Maas, C. Copéret, D. Farrusseng, L. Emsley, A. Lesage, Angew. Chem. Int. Ed. 2012, 51, 123.

[50] A. Zagdoun, G. Casano, O. Ouari, G. Lapadula, A. J. Rossini, M. Lelli, M. Baffert, D. Gajan, L. Veyre, W. E. Maas, M. Rosay, R. T. Weber, C. Thieuleux, C. Copéret, A. Lesage, P. Tordo, L Emsley, J. Am. Chem. Soc. 2011, 134, 2284. 